\title{
Analyzing Dynamic Impacts of Deagriculturalization on CO2 Emissions in Selected Asian Economies: A Tale of Two Shocks
}

\section{Siyuan Lin}

Nanjing University of Finance and Economics

Ning Zhou

Nanjing University of Finance and Economics

Junaid Jahangir

Shanxi University of Finance and Economics

Sidra Sohail ( $\square$ sidrasohail_14@pide.edu.pk)

Pakistan Institute of Development Economics

\section{Research Article}

Keywords: CO2 emissions, Deagriculturalization, selected Asian economies

Posted Date: January 7th, 2022

DOI: https://doi.org/10.21203/rs.3.rs-845496/v1

License: (c) (i) This work is licensed under a Creative Commons Attribution 4.0 International License. Read Full License 
Analyzing Dynamic Impacts of Deagriculturalization on CO2 Emissions in Selected Asian Economies: A Tale of Two Shocks

\title{
Siyuan Lin
}

Institute of Food and Strategic Reserves, Nanjing University of Finance and Economics, Nanjing 210023, Jiangsu, China. zhangsanfeng@gdou.edu.cn

\author{
Ning Zhou \\ School of Economics, Nanjing University of Finance \& Economics, Texs 210023, China. \\ njzhouning@foxmail.com \\ Junaid Jahangir \\ School of Business Administration, Shanxi University of Finance and Economics, Taiyuan, China. \\ Junaedmughal@gmail.com \\ Sidra Sohail** \\ **Corresponding author \\ Pakistan Institute of Development Economics (PIDE) Islamabad, Pakistan. sidrasohail_14@pide.edu.pk
}

\begin{abstract}
The study investigates the symmetric and asymmetric impact of agriculturalization on environmental quality in sample of selected Asian economies for time period 1991 to 2019. For empirical analysis, the study adopted ARDL-PMG and NARDL-PMG approaches. The long-run findings of ARDL-PMG reveal that agriculturalization tends to significantly improve the quality of environment. The empirical outcomes of NARDL-PMG infer that positive shock in agriculturalization results in enhancing environmental quality, however, the negative shock in agriculturalization (i.e., de-agriculturalization) leads to deterioration of environmental quality in the long-run. The findings demonstrate that agriculturalization improves environmental quality and de-agriculturalization mitigates environmental quality. Based on these findings, the study recommends that the relevant authorities should formulate such reforms in the agriculture sector that controls and reduces carbon emissions in Asian economies.
\end{abstract}

Keywords: $\mathrm{CO} 2$ emissions. Deagriculturalization. selected Asian economies

\section{Introduction}

World's population has grown from 1 billion in 1800 to 7.9 billion in 2020. This massive rise in the population has increased the demand for food manifold. Consequently, the importance of the agriculture sector has also increased as it provides food to billions of people. Moreover, agriculture has become an essential factor 
in achieving sustainable economic development, and Higgs (1987) also supported this claim. In the literature, Sertoglu et al. (2017) and Victor Bekun and Akadiri (2019) provide strong enough evidence to support the idea that agriculture is crucial for economic growth. However, finding the path through which agriculture can help achieve long-term economic growth is an important question that still needs an appropriate answer from academics, empirics, and policymakers.

Several pieces of empirical evidence are available that sustain the idea that agriculture is vital in the

49 long-term economic growth of the economy by selling agricultural products to other economies (Balassa 1978; Voivodas 1973). Conversely, some studies don't support the favorable impact of agriculture on economic growth. For instance, Tiffin and Irz (2006) gathered data for 85 countries over the period 1960-1971 and confirmed the positive effects of the agriculture sector on the economic growth in emerging nations but not in the developed nations. Among other factors, ineffective export strategies are the common cause behind the noncontribution of the agriculture sector in promoting economic growth (Shaikh, 2011). This notion is upheld by another study that targets an agricultural country like Pakistan and recognized that agricultural-related exports do not help attain long-term economic growth objectives in Pakistan (Ullah et al. 2021).

Moreover, due to the rising population, the demand for agricultural products is also on the rise. Consequently, the energy demand also rises in a bid to produce agricultural products for the rising population. As far as developing economies are concerned, their energy mix is primarily composed of non-renewable energy (Majeed and Luni 2019), the main source of increased greenhouse gas (GHG) emissions in the ecosystem. Therefore, the progress of the agriculture sector is not free of cost; instead comes at the expense of environmental degradation (Gokmenoglu and Taspinar 2018). Food and Agricultural Organisation (FAO) highlighted that the agricultural sector is responsible for almost one-third of the total worldwide GHG emissions; hence, it has a vital role in degrading the environment (FAO, 2016). The adverse effects of the agricultural sector have further escalated after the food crisis of 2006-2008, and this sector ranked second among the contributors of global GHG emissions. One of the most significant consequences of agriculture is deforestation which degrades the environment significantly. Forest provides the wood for cooking and heating purposes in the rural areas of developing economies, emitting $\mathrm{CO} 2$ emissions. Moreover, the agricultural sector involves activities such as burning bushes and biomass (Ramachandra et al., 2015). However, according to a report published by FAO in the year 2016, the agriculture sector has the ability to cut down its currently produced GHG emissions by $20 \%-60 \%$ at the end of the year 2030. The harmful effects of the agriculture sector on environmental quality can be reduced by discouraging deforestation, using innovative varieties of plants, applying good quality fertilizers, and adopting green and renewable energy (Reynolds et al. 2015; Mohamad et al. 2016; Liu et al. 2017).

Existing literature on the nexus between environment and agriculture pointed out a variety of agricultural practices that can affect environmental quality. Pretty (2008) highlighted that the association between environment and agriculture relies on the techniques used in the agricultural sector. Cultivation can upsurge $\mathrm{CO} 2$ releases if biological leftover increases in the land. On the other side, instead of burning the waste, we can use it to produce renewable energy that would help to mitigate $\mathrm{CO} 2$ emissions in the environment. Besides, sustainable agricultural methods have various advantages, such as a rise in per acre yield, a decline in pesticide use, and low carbon emissions in the atmosphere. 
A plethora of studies is available that have examined the role of the agricultural sector as a determinant of environmental quality in various economies. Couwenberg et al. (2010) analyzed the influence of peat soil, rice paddy, and fertilizers on the ecological quality of the countries of Southeast Asia by employing metaanalysis. Their findings confirmed that peatland rewetting upsurged methane and carbon discharges. Hughes et al. (2011) observed that fungicide therapy helps improve environmental quality in the United Kingdom. In the context of China, Zhang et al. (2015), tried to investigate the effects of various crop traits such as harvest, residues, and its process on $\mathrm{CO} 2$ emissions by using the symmetric framework. Their outcomes suggested that remainders of crops degraded the environmental quality. Similarly, Zahoor et al. (2015) highlighted that nitrous oxide (N2O) emissions increased due to agricultural activities and contributes to environmental pollution and global warming. Hou et al. (2015) pointed out that livestock activities enhance CO2 emissions; however, its effects can be mitigated through effective farm management. Likewise, Mariantonietta et al. (2018) also supported the idea that efficient farm management can help reduce livestock-related carbon emissions.

Although the previous literature provided enough evidence on the relationship between agriculture and environmental quality, the findings are inconclusive. The implied reasons could be the application of different data sets and estimation techniques. Furthermore, the results are sensitive to the difference in agricultural methods observed in various countries. All the previous studies have one thing in common: they ignore the agricultural variables' nonlinear behavior, which is very common in the agriculture sector due to its vulnerability to external shocks. Lastly, most studies have ignored the Asian economies, which heavily rely on the agriculture sector. Hence, this study is an effort to find dynamic impacts of de-agriculturalization on the $\mathrm{CO} 2$ emissions in five Asian economies India, Japan, Korea, Pakistan, and Thailand. However, in this study, we have focused on the asymmetric effects of de-agriculturalization on the environmental quality in selected Asian economies. To that end, we have employed linear and nonlinear panel ARDL techniques, which are robust to find the asymmetric effects of the variables and provide efficient results even if the sample size is small. This study will also provide essential policy directives for all stakeholders.

The selection of Asian economies is not by chance but instead based on the fact that the contribution of agriculture to the total GDP of Asian economies is about 10\%-15\%. However, agricultural production in Asian regions is severely threatened due to climate change, mainly in tropical areas. Per acre yields are anticipated to decline rapidly in tropical regions such as South and Southeast Asia in the current century. According to Asian Development Bank (ADB, 2009), there is a fear that per acre yield will decline by $50 \%$ at the end of the $21^{\text {st }}$ century compared to the yield in the 1990s. And the agriculture sector itself is a significant contributor to global GHG emissions; hence, studying the impact of the agriculture sector on the $\mathrm{CO} 2$ emissions in Asian economies is pertinent, from the point of view of food security and sustainable economic development.

The organization of the study is as follows. The model and methods is described in the next section, followed by data in section three. In section three, we provide the results and conclusion in section four.

\section{Model and methods}

119 A review of literature in the previous section revealed that most studies have included agriculturalization in their formulation of $\mathrm{CO} 2$ emissions. Following the empirical literature especially Ullah et al. (2021) who carried out 
a similar analysis for the Pakistan economy, we assume that selected Asian's CO2 emissions take the following

122

123

124

125

126

127

128

129

131

132

133

134

135

136

137

138

139

140

141

142

143

144

145

146

147

148

149

150

151

152

$$
\mathrm{CO}_{2, \mathrm{t}}=\varphi_{0}+\varphi_{1} \mathrm{AVA}_{\mathrm{t}}+\varphi_{2} \mathrm{GDP}_{\mathrm{t}}+\varphi_{2} \mathrm{EC}_{\mathrm{t}}+\varphi_{3} \mathrm{Urb}_{\mathrm{t}}+\varphi_{4} \mathrm{FD}_{\mathrm{t}}+\varepsilon_{\mathrm{t}}
$$

Equation (1) represents selected Asian's $\mathrm{CO} 2$ emissions to depend on the agriculturalization (AVA), GDP per capita (GDP), energy consumption (EC), urbanization (Urb), financial development (FD). We expect estimates of agriculturalization elasticity's to be negative in the $\mathrm{CO} 2$ emissions model. While coefficient estimates from (1) are long-run estimates. In order to measure the short-run effects of $\mathrm{CO} 2$ emissions, we follow Pesaran et al. (2001) error-correction formats and re-write equation (1) is as follows:

$$
\begin{aligned}
\Delta \mathrm{CO}_{2, \mathrm{t}}=\alpha_{0}+ & \sum_{\mathrm{i}=1}^{\mathrm{p}} \pi_{1 \mathrm{k}} \Delta \mathrm{CO}_{2, \mathrm{t}-\mathrm{i}}+\sum_{\mathrm{i}=0}^{\mathrm{p}} \pi_{2 \mathrm{k}} \Delta \mathrm{AVA}_{\mathrm{t}-\mathrm{i}}+\sum_{\mathrm{i}=0}^{\mathrm{p}} \pi_{3 \mathrm{k}} \Delta \mathrm{GDP}_{\mathrm{t}-\mathrm{i}}+\sum_{\mathrm{i}=0}^{\mathrm{p}} \pi_{4 \mathrm{k}} \mathrm{EC}_{\mathrm{t}-\mathrm{i}}+\sum_{\mathrm{i}=0}^{\mathrm{p}} \pi_{5 \mathrm{k}} \mathrm{Urb}_{\mathrm{t}-\mathrm{i}} \\
& +\sum_{\mathrm{i}=0}^{\mathrm{p}} \pi_{6 \mathrm{k}} \mathrm{FD}_{\mathrm{t}-\mathrm{i}}+\omega_{1} \mathrm{CO}_{2, \mathrm{t}-1}+\omega_{2} \mathrm{AVA}_{\mathrm{t}-1}+\omega_{3} \mathrm{GDP}_{\mathrm{t}-1}+\omega_{4} \mathrm{EC}_{\mathrm{t}-1}+\omega_{5} \mathrm{Urb}_{\mathrm{t}-1} \\
& +\omega_{6} \mathrm{FD}_{\mathrm{t}-1}+\lambda \cdot \mathrm{ECM}_{\mathrm{t}-1}+\varepsilon_{\mathrm{t}}
\end{aligned}
$$

Specification such as (2) is due to Pesaran et al. (2001) who represent the short-run coefficients estimates $\pi_{1 \mathrm{k}^{-}}$ $\pi_{6 \mathrm{k}}$ and the long-run coefficients estimates of $\omega_{2}-\omega_{6}$ normalized on $\omega_{1}$. Conversely, to avoid the problem of spurious regression, we must determine cointegration. Pesaran et al. (2001) suggest two basic diagnostics tests, firstly, a standard F-test to establish the joint level of significance of the lagged-level variables in model, and secondly, t-test to establish the significance level in the equation (2). Both diagnostic tests have used their own tabulate new critical values. Indeed, there is no need for pre-unit root testing, because macro variables could be a combination of $\mathrm{I}(0)$ and $\mathrm{I}(1)$, this is one of the key edges of this method. There is also one advantage of this method in addition to being able to estimate the long-run and short-run impacts in one step. In equation (2) it is generally assumed that agriculturalization changes have symmetric or linear effects on Asia's CO2 emissions. Shin et al. (2014) modify equations like (2) so that we can use them to easily detect the likelihood of asymmetric effects. Accordingly, we must separate positive change $\left(\mathrm{AVA}^{+}\right)$from negative change (AVA') using the partial sum concept as follows:

$$
\begin{aligned}
& \mathrm{AVA}_{\mathrm{t}}=\sum_{\mathrm{n}=1}^{\mathrm{t}} \Delta \mathrm{AVA}_{\mathrm{t}}^{+}=\sum_{\mathrm{n}=1}^{\mathrm{t}} \max \left(\Delta \mathrm{AVA}^{+}{ }_{\mathrm{t}}, 0\right) \\
& \mathrm{AVA}^{-}{ }_{\mathrm{t}}=\sum_{\mathrm{n}=1}^{\mathrm{t}} \Delta \mathrm{AVA}^{-}{ }_{\mathrm{t}}=\sum_{\mathrm{n}=1}^{\mathrm{t}} \min \left(\Delta \mathrm{AVA}^{-}{ }_{\mathrm{t}}, 0\right)
\end{aligned}
$$

In equations ( $3 \& 4), \mathrm{AVA}^{+}$which is the positive changes in the agriculturalization is a new time-series variable and $\mathrm{AVA}^{-}$is the partial sum of negative changes in agriculturalization (i.e., de-agriculturalization). Next, we replace the new partial sum variables to arrive at:

$$
\begin{aligned}
\Delta \mathrm{CO}_{2, \mathrm{t}}=\alpha_{0}+ & \sum_{\mathrm{i}=1}^{\mathrm{p}} \pi_{1 \mathrm{k}} \Delta \mathrm{CO}_{2, \mathrm{t}-\mathrm{i}}+\sum_{\mathrm{i}=0}^{\mathrm{p}} \pi_{2 \mathrm{k}} \Delta \mathrm{AVA}_{\mathrm{t}-\mathrm{i}}^{+}+\sum_{\mathrm{i}=0}^{\mathrm{p}} \pi_{3 \mathrm{k}} \Delta \mathrm{AVA}_{\mathrm{t}-\mathrm{i}}+\sum_{\mathrm{i}=0}^{\mathrm{p}} \pi_{4 \mathrm{k}} \Delta \mathrm{GDP}_{\mathrm{t}-\mathrm{i}}+\sum_{\mathrm{i}=0}^{\mathrm{p}} \pi_{5 \mathrm{k}} \mathrm{EC}_{\mathrm{t}-\mathrm{i}} \\
& +\sum_{\mathrm{i}=0}^{\mathrm{p}} \pi_{6 \mathrm{k}} \mathrm{Urb}_{\mathrm{t}-\mathrm{i}}+\sum_{\mathrm{i}=0}^{\mathrm{p}} \pi_{7 \mathrm{k}} \mathrm{FD}_{\mathrm{t}-\mathrm{i}}+\omega_{1} \mathrm{CO}_{2, \mathrm{t}-1}+\omega_{2} \mathrm{AVA}_{\mathrm{t}-1}^{+}+\omega_{3} \mathrm{AVA}_{\mathrm{t}-1}^{-}+\omega_{4} \mathrm{GDP}_{\mathrm{t}-1} \\
& +\omega_{5} \mathrm{EC}_{\mathrm{t}-1}+\omega_{6} \mathrm{Urb}_{\mathrm{t}-1}+\omega_{7} \mathrm{FD}_{\mathrm{t}-1}+\lambda \cdot \mathrm{ECM}_{\mathrm{t}-1}+\varepsilon_{\mathrm{t}}
\end{aligned}
$$


Since the construction of the partial sum variables introduces nonlinearity into specifications (2) is called linear ARDL model, while specification like (6) is called non-linear ARDL models. Linear and nonlinear ARDL models are estimated by OLS and are all subject to the same diagnostic tests, except Wald-test. Wald test is employed to a tested the assumption of asymmetric effects of agriculturalization on Asian's CO2 emissions. Short-run asymmetric effects will be established if we rejected the null hypothesis of Wald test $\left(\sum \delta_{2 \mathrm{k}}=\sum \delta_{3 \mathrm{k}}\right)$. Lastly, the long-run asymmetric impacts between the positive and negative changes are established if, once again, we can reject the null hypothesis of Wald test $\left(\frac{\omega_{2}}{-\omega_{1}}=\frac{\omega_{3}}{-\omega_{1}}\right)$.

For robustness, we also employed fully modified OLS (FMOLS) and dynamic OLS (DOLS) methods are chosen to estimate the coefficient estimates. Both econometric approaches are widely used in empirical panel studies. The reason is that scholars claim that the PMOLS is superior to the DOLS method since it remedies several econometric issues of economics such as endogeneity, autocorrelation, and simultaneity biasness (Dogan and Seker, 2016), along with providing reliable results in small sample in panel model. The FMOLS is considered non-parametric approach, while DOLS method eradicates the concerns through parametric approach (Kao \& Chiang, 2000). Kao and Chiang (2000) compared the coefficient estimates of POLS, DOLS, and FMOLS by using Monte Carlo simulations. According to their empirical analysis, DOLS estimator better performs than OLS and FMOLS. To avoid possible uncertainty in empirical robust results in symmetric and asymmetric models, we selected both methods, i.e., FMOLS and DOLS.

Panel quantile regression method is in accordance with the studies of Zhang et al. (2016). We employ panel quantile regression for exploring variation of $\mathrm{CO} 2$ emissions within OECD regions. For employing a panel quantile regression approach, we introduce the th quantile of the conditional distribution of $\mathrm{CO} 2$ emissions given concern variables. We also consider 11 quantiles, $t$ th $(0.05,0.10,0.20,0.30,0.40,0.50,0.60$, $0.70,0.80,0.90,0.95)$. The median $(0.50)$ quantile reflects the normal agriculture condition. Furthermore, to compare the results of the traditional mean regression method and panel quantile regression method in the next section. Thus, we examine the asymmetric relationship between deagriculturalization on $\mathrm{CO} 2$ emissions, we use the NARDL-PMG, FMOLS, DOLS, and quantile regression approach.

\section{Data}

Our data sample consists of panel data of six selected Asian countries (India, Japan, Korea, China, Pakistan, and Thailand), covering the period 1991-2019, which are obtained from the database of the World Bank (2020). Notably, we consider the $\mathrm{CO} 2$ emissions in kilotons as the dependent variable, while the independent key factor is key agriculturalization. While, the control variables are GDP, energy consumption, financial development, and urbanization. As Ullah et al. (2021) used agricultural value-added as a proxy for agriculturalization, we have used the same definition for our study. For better estimates and expressing large numbers, all variables are converted to the logarithmic form in this study. The descriptive statistics are reported in Table 1, which specify that the average values of CO2, AVA, GDP, EC, FD, and Urb, are 12.98, 11.52. 8.340, 7.231, 4.194, and 53.41 and the standard deviations are $0.989,9.063,1.664,0.986,0.821$, and 24.53 , respectively. 


\begin{tabular}{|c|c|c|c|c|c|c|}
\hline Variables & Symbol & Definitions & Mean & $\begin{array}{l}\text { Std. } \\
\text { Dev. }\end{array}$ & Min & Max \\
\hline CO2 emissions (kt) & $\mathrm{CO} 2$ & CO2 emissions (kt) & 12.98 & 0.989 & 11.00 & 14.70 \\
\hline Agriculturalization & AVA & $\begin{array}{l}\text { Agriculture, forestry, and fishing, value added } \\
\text { (\% of GDP) }\end{array}$ & 11.52 & 9.063 & 0.939 & 27.33 \\
\hline $\begin{array}{l}\text { Gross domestic } \\
\text { product }\end{array}$ & GDP & GDP per capita (current US\$) & 8.340 & 1.664 & 5.708 & 10.79 \\
\hline Energy consumption & EC & Energy use (kg of oil equivalent per capita) & 7.231 & 0.986 & 5.879 & 8.707 \\
\hline Financial development & FD & Domestic credit to private sector (\% of GDP) & 4.194 & 0.821 & 2.730 & 5.391 \\
\hline Urbanization & Urb & Urban population (\% of total population) & 53.41 & 24.53 & 25.77 & 91.69 \\
\hline
\end{tabular}

194

195

196

\section{Results and discussion}

In this study, our goal is to estimate the effects of deagriculturalization on the $\mathrm{CO} 2$ emissions in selected Asian economies, i.e., India, Japan, Korea, China, Pakistan, and Thailand. To that end, we have applied linear and nonlinear panel ARDL-PMG as baseline models. Then, to check the robustness of our results, we have used linear and nonlinear FMOLS and DOLS, and lastly, the asymmetric quantile regression analysis. However, before applying ARDL \& NARDL-PMG, we need to confirm the stationarity of our variables. For that purpose, we have applied two-panel unit root tests Levin, Lin, and Chu (LLC) and ADF-Fisher. From table 2, we deduce that both the tests confirm that most of the selected variables are a mixture of I(0) and I(1); thus, panel-ARDL is justifiable. Next, as our data is annual, the analysis applied a maximum of two lags, and to select appropriate lags, we imposed Akaike Information Criterion (AIC).

Table 2: Panel unit root testing

\begin{tabular}{|c|c|c|c|c|c|c|}
\hline & LLC & & & ADF & & \\
\hline & $I(0)$ & I(1) & Decision & $I(0)$ & I(1) & Decision \\
\hline $\mathrm{CO} 2$ & $-1.875^{* *}$ & & $I(0)$ & $-1.764 * *$ & & $I(0)$ \\
\hline AVA & $-5.553 * * *$ & & $I(0)$ & $-2.837 * * *$ & & $I(0)$ \\
\hline GDP & -0.345 & $-5.875 * * *$ & $\mathrm{I}(1)$ & -0.365 & $-7.452 * * *$ & $\mathrm{I}(1)$ \\
\hline $\mathrm{EC}$ & $-1.920 * *$ & & $\mathrm{I}(0)$ & -0.365 & $-4.655 * * *$ & $\mathrm{I}(1)$ \\
\hline FD & $-1.987 * *$ & & $I(0)$ & -0.365 & $-5.492 * * *$ & $\mathrm{I}(1)$ \\
\hline Urb & -0.355 & $-1.654^{*}$ & $I(1)$ & $-2.961 * * *$ & & $I(0)$ \\
\hline
\end{tabular}

Note: $* * * \mathrm{p}<0.01 ; * * \mathrm{p}<0.05 ;$ and $* \mathrm{p}<0.1$

Table 3 provides the estimate of linear and nonlinear ARDL estimates alongside the estimate of cointegration tests. The validity of long-run results depends on the outcomes of cointegration tests, namely $\mathrm{ECM}_{\mathrm{t}-1}$ and F-test. Both the tests confirm that our variables are cointegrated; in other words, the long-run relationship between $\mathrm{CO} 2$, AVA, GDP, EC, FD, and Urb is not spurious.

From Table 3, we confer that the estimated coefficient of AVA in the linear ARDL-PMG is negatively significant, implying that a $1 \%$ rise in AVA decreases the CO2 emissions. Similarly, in the nonlinear ARDLPMG, the estimates attached to AVA_POS \& AVA_NEG are negatively significant. Numerically, we can say that a $1 \%$ rise in AVA causes the CO2 emissions to decrease by $0.046 \%$, whereas a $1 \%$ decline in the AVA 
causes the $\mathrm{CO} 2$ emissions to rise by $0.017 \%$. Both linear and nonlinear findings complement each other and the magnitude of both the linear and nonlinear estimates are almost similar. However, the nonlinear estimates provide an additional estimate that gives us information regarding the effect of negative shock in AVA on environmental quality. The size of negative shock is less than the positive shock, which implies that a rise in AVA will improve the environmental quality more as compared to the degradation in the environmental quality caused by the negative shock in AVA. Seeing the behavior of asymmetric estimates, we can confirm that $\mathrm{CO} 2$ emissions respond asymmetrically to the positive and negative shocks, and the asymmetric effects are also confirmed via a significant estimate of WALD-LR reported in Table 3.

Generally, our findings suggest that excessive deagriculturalization improves the environment of selected Asian economies; however, deagriculturalization degrades the environmental quality by increasing $\mathrm{CO} 2$ emissions. The agriculture sector can either improve or degrade the environmental quality. According to FAO, agriculture-driven GHG emissions are about one-third of the total global emissions (FOA, 2016). However, FAO also highlighted that the agriculture sector has the ability to reduce its currently produced $\mathrm{CO} 2$ emissions down by $20 \%-60 \%$ at the end of the year 2030 . The agriculture sector can improve the environmental quality by using renewable energy sources (Reynolds et al. 2015; Mohamad et al. 2016; Liu et al. 2017) as it requires energy for plowing, irrigation, harvesting, and livestock activities. Instead of burning the crops residues, bushes, and wastes, farmers can use them to produce renewable energy, which helps to reduce $\mathrm{CO} 2$ emissions. Increased agriculturalistaion can increase plantation and crops, which speed up photosynthesis and consequently mitigate $\mathrm{CO} 2$ emissions. Furthermore, improvement in agriculture-related infrastructures such as water reservoirs, agricultural transmission amenities, commodities production base, and rural weather casting framework can help modernize the rural areas, eventually improving the rural economy without exerting more burden on the environment (Dhehibi et al. 2016). Better farm management can also help to reduce livestockrelated CO2 emissions (Hou et al. 2015 and Mariantonietta et al. 2018).

Table 3: ARDL and NARDL estimates

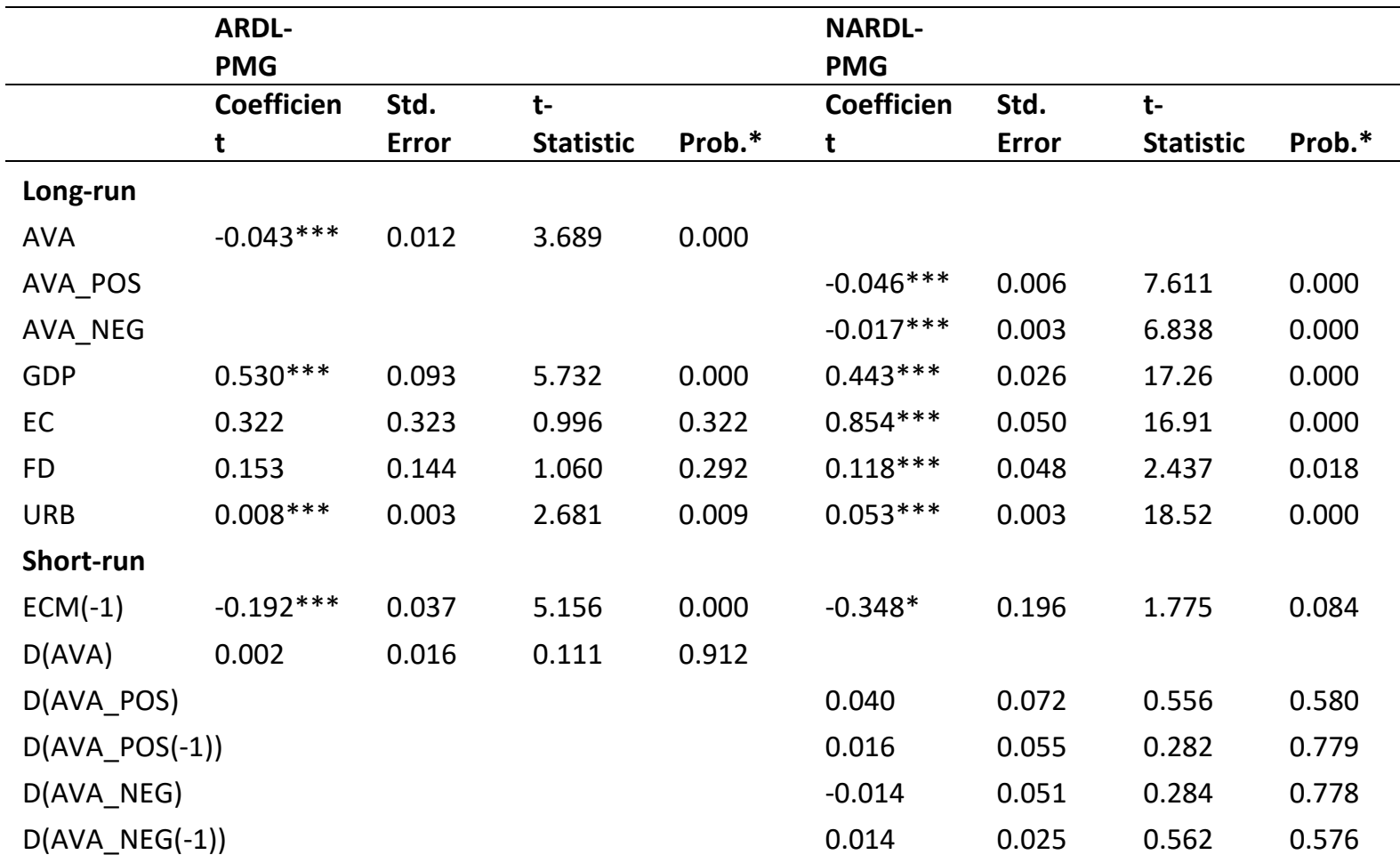




\begin{tabular}{|c|c|c|c|c|c|c|c|c|}
\hline $\mathrm{D}(\mathrm{GDP})$ & $-0.030^{*}$ & 0.018 & 1.674 & 0.097 & $-0.133^{*}$ & 0.080 & 1.662 & 0.100 \\
\hline $\mathrm{D}(\mathrm{GDP}(-1))$ & & & & & -0.058 & 0.111 & 0.522 & 0.604 \\
\hline $\mathrm{D}(\mathrm{EC})$ & $0.694^{* * *}$ & 0.157 & 4.419 & 0.000 & 0.181 & 0.515 & 0.352 & 0.726 \\
\hline $\mathrm{D}(\mathrm{EC}(-1))$ & & & & & -0.083 & 0.073 & 1.147 & 0.256 \\
\hline $\mathrm{D}(\mathrm{FD})$ & $0.116 *$ & 0.070 & 1.666 & 0.100 & $-0.173^{*}$ & 0.100 & 1.730 & 0.089 \\
\hline $\mathrm{D}(\mathrm{FD}(-1))$ & & & & & -0.127 & 0.100 & 1.265 & 0.210 \\
\hline $\mathrm{D}(\mathrm{URB})$ & -0.152 & 0.136 & 1.119 & 0.266 & -0.220 & 0.273 & 0.805 & 0.424 \\
\hline $\mathrm{D}(\mathrm{URB}(-1))$ & & & & & 0.289 & 0.270 & 1.070 & 0.289 \\
\hline C & $1.551^{* * *}$ & 0.317 & 4.897 & 0.000 & 2.189 & 1.362 & 1.607 & 0.113 \\
\hline \multicolumn{9}{|l|}{ Diagnostics } \\
\hline F-test & $5.651^{* * *}$ & & & & $7.655^{* * *}$ & & & \\
\hline $\begin{array}{l}\text { Log- } \\
\text { likelihood }\end{array}$ & 342.5 & & & & 365.5 & & & \\
\hline Wald-LR & & & & & $5.356 * * *$ & & & \\
\hline Wald-SR & & & & & 1.325 & & & \\
\hline
\end{tabular}

Note: $* * * \mathrm{p}<0.01 ; * * \mathrm{p}<0.05 ;$ and ${ }^{*} \mathrm{p}<0$.

The estimates attached to the control variables of GDP are positively significant in linear and nonlinear ARDL-PMG, suggesting the supporting role of economic activities on $\mathrm{CO} 2$ emissions. However, the estimates of EC and FD are also positive in both the base models; however, significant in NARDL-PMG and insignificant in ARDL-PMG. However, URB exerts a positive and significant impact on $\mathrm{CO} 2$ emissions in both the linear and nonlinear base models. Overall, we can say that energy consumption, financial development, and urbanization contribute to environmental degradation, in Asian economies, besides GDP growth and agriculturalization.

The results of robust models are displayed in Table 4. The estimates attached to AVA in the linear FMOLS and DOLS are negatively significant. In a more precise way, we can say that a $1 \%$ rise in agriculturerelated activities in the selected Asian economies reduces the $\mathrm{CO} 2$ emissions by $0.01 \%$ in both FOLS and DOLS models. When we turn our attention to the nonlinear FMOLS and DOLS models, we can see that the estimated coefficients of AVA_POS and AVA_NEG are negatively significant in both models. More specifically, a $1 \%$ rise or positive shock in agricultural activities reduces the $\mathrm{CO} 2$ emissions by $0.04 \%$ in FMOLS models and $0.05 \%$ in the DOLS model. Conversely, a $1 \%$ fall or negative shock in the agriculture sector increases the $\mathrm{CO} 2$ emissions by $0.01 \%$ in FMOLS and 0.17\% in the DOLS model. The findings of our robust model support the outcomes of our basic model, and both suggest that agriculturalization improves environmental quality in selected Asian economies; whereas, deagriculturalization degrade the environmental quality. Moreover, the size of the estimates in the baseline models and robust models are also similar, which further confirms the results of the baseline models. Like our baseline models, the estimated coefficients of GDP, EC, FD, and Urb are positively significant in the linear and nonlinear FMOLS and DOLS models, implying an increase in economic activities, urbanization, energy consumption, and financial development all degrade the environmental quality. 


\begin{tabular}{lllll}
\hline \multicolumn{4}{l}{ Model without asymmetry } & \multicolumn{2}{l}{ Model without asymmetry } \\
\hline AVA & FMOLS & DOLS & FMOLS & DOLS \\
& $-0.01^{* * *}$ & $-0.01^{* * *}$ & & \\
AVA_POS & $(10.6)$ & $(10.7)$ & & $-0.05^{* * *}$ \\
& & & $-0.04^{* * *}$ & $(6.52)$ \\
AVA_POS & & $(9.26)$ & $-0.17^{* * *}$ \\
& & & $-0.01^{* * *}$ & $(9.24)$ \\
GDP & & & $(5.65)$ & $0.17^{* * *}$ \\
& $0.07^{* * *}$ & $0.04^{* * *}$ & $0.08^{* * *}$ & $(8.58)$ \\
EC & $(29.1)$ & $(9.09)$ & $(34.07)$ & $0.26^{* * *}$ \\
& $1.04^{* * *}$ & $0.72^{* * *}$ & $0.93^{* * *}$ & $(6.62)$ \\
FD & $(9.37)$ & $(8.35)$ & $(8.46)$ & $0.89^{* * *}$ \\
& $0.02^{* * *}$ & $0.30^{* * *}$ & $0.01^{* * *}$ & $(2.81)$ \\
Urb & $(11.7)$ & $(4.14)$ & $(11.9)$ & $0.08^{* * *}$ \\
& $0.04^{* * *}$ & $0.07^{* * *}$ & $0.05^{* * *}$ & $(10.4)$ \\
\hline
\end{tabular}

271

272

Table 5: Asymmetric panel quantile regression

\begin{tabular}{lllllll}
\hline & AVA_POS & AVA_NEG & GDP & EC & FD & Urb \\
\hline 0.05 & 0.057 & 0.017 & 0.132 & $2.136^{*}$ & -0.662 & $-0.039 * * *$ \\
0.10 & 0.072 & 0.015 & 0.171 & $2.175^{* * *}$ & -0.801 & $-0.040^{* * *}$ \\
0.20 & 0.068 & -0.015 & 0.415 & $2.092^{* * *}$ & -1.085 & $-0.046^{* * *}$ \\
0.30 & 0.123 & 0.071 & $0.969 *$ & $1.507^{* * *}$ & $-0.934^{* *}$ & $-0.055^{* * *}$ \\
0.40 & -0.175 & -0.097 & 2.252 & 0.688 & -1.574 & $-0.092^{*}$ \\
0.50 & $-0.441^{* * *}$ & $-0.138^{* * *}$ & $2.575^{* * *}$ & $1.239 * * *$ & $-2.153^{* * *}$ & $-0.151^{* * *}$ \\
0.60 & $-0.479 * * *$ & $-0.120^{* *}$ & $2.546^{* * *}$ & $1.496^{* * *}$ & $-2.336^{* * *}$ & $-0.159 * * *$ \\
0.70 & $-0.492^{* * *}$ & $-0.198^{*}$ & 1.115 & $2.668^{* * *}$ & $-2.416^{* * *}$ & -0.086 \\
0.80 & $-0.525^{* * *}$ & $-0.182^{* *}$ & 0.702 & $3.216^{* * *}$ & $-2.551^{* * *}$ & -0.076 \\
0.90 & $-0.575^{* * *}$ & $-0.162 *$ & 1.111 & $3.122 * * *$ & $-2.902 * * *$ & -0.092 \\
0.95 & $-0.593^{* * *}$ & $-0.149 * *$ & 1.232 & $3.091^{* * *}$ & $-2.964 * * *$ & $-0.098^{* *}$ \\
\hline
\end{tabular}

Table 5 portrays the results of quantile regression estimates. Although we have presented the complete results of all our variables; however, to save space, we only discuss the results of our primary variable. In total, we have included 11 quantiles. The estimates of AVA_POS and AVA_NEG are insignificant from the 5 th $^{\text {th }}$ quantile to the $40^{\text {th }}$ quantile. However, for the rest of the quantiles, the estimates of AVA_POS and AVA_NEG are significant and negative. As far as the effects of AVA_POS on the CO2 emissions are concerned, the estimates are continuously rising from $0.441 \%$ in the $50^{\text {th }}$ quantile to $0.593 \%$ in the $95^{\text {th }}$ quantile. Generally speaking, the higher will be agriculture-related activities more will be the improvement in the environmental quality. On the other side, the estimates of AVA_NEG decrease from $50^{\text {th }}$ quantile to $60^{\text {th }}$ quantile. It increases again in the $70^{\text {th }}$ quantile, and after that, it decreases continuously till the $95^{\text {th }}$ quantile. The results AVA_NEG suggest that deagriculturalization degrades the environmental quality; however, its impact is most severe in the $70^{\text {th }}$ quantile and least in the $60^{\text {th }}$ quantile.

Note: $* * * p<0.01 ; * * p<0.05$; and $* p<0.1$ 
The existing literature on agriculturalization and environmental pollution has been overwhelmed with ambiguous findings. As several studies reveal a clear association between agriculturalization and degradation of environment which provides no clear discrepancy between carbon emissions stemming from agricultural modernization and pollution emissions persuaded by various cultivation strategies and practices. The study makes an effort to explore the asymmetric impact of agriculturalization on $\mathrm{CO} 2$ emissions in six Asian economies such as India, Japan, China, Korea, Pakistan, and Thailand for time horizon 1991 to 2019. For conducting regression analysis, the study employed ARDL-PMG and NARDL-PMG techniques. The long-run outcomes of ARDL-PMG infer that agriculturalization has a significant negative impact on $\mathrm{CO} 2$ emissions revealing that in response to an increase in agricultural activities, the quality of the environment will rise. The findings of NARDL-PMG deduce that positive shock in agriculturalization infer a significant negative impact on $\mathrm{CO} 2$ emissions and negative shock in agriculturalization (i.e., de-agriculturalization) has a significant positive impact on $\mathrm{CO} 2$ emissions. In short, according to NARDL-PMG findings, agriculturalization tends to enhance environmental quality and de-agriculturalization leads to diminishing the quality of environment in the long-run. The study also incorporated the impact of some important control variables such as GDP, energy use, financial development, and urbanization on carbon emissions in selected Asian economies. The NARDL-PMG findings of these control variables demonstrate that all these factors significantly increase carbon emissions in the long-run in these economies. However, the findings do not report any symmetric and asymmetric association between agriculturalization and $\mathrm{CO} 2$ emissions in the short-run. For robustness testing, the study employed FMOLS and DOLS regression techniques. The empirical outcomes of robust models are quite similar to the findings of ARDL-PMG and NARDL-PMG approaches.

Given our empirical results, the government and policymakers need to emphasize organic farming in selected Asian economies. The governments should emphasize zero tillage, organic farming, irrigation monitoring, drones, and biotechnology that would help in the reduction of environmental pollution in Pakistan. The policymaker should use more clean energy consumption in agricultural activities. The Asian governments can encourage green agricultural revolution by adopting an incentive mechanism. The outcomes of the empirical study can be a guideline and blueprint for other agrarian countries to tackle the problem of deagriculturalization for the creation of effective policies around environmental quality. Government should be established and empowered to control and reduce agriculture-based pollution in Asian economies. Asian government should increase environmental quality by improving green agriculturalization.

There are still several avenues for future research. The present study is done for Asian economies at the aggregate level, in the future, the same study can also be done for disaggregated level considering these economies. Furthermore, the same model can be tested for other regions and developing economies, especially for newly emerging economies.

Ethical Approval: Not applicable

322 Consent to Participate: I am free to contact any of the people involved in the research to seek further clarification and information

324 Consent to Publish: Not applicable 
Authors Contributions: This idea was given by Siyuan Lin. Siyuan Lin, Ning Zhou, and Junaid Jahangir analyzed the data and wrote the complete paper. While, Sidra Sohail read and approved the final version. Funding: This work was supported by Social Science Foundation Major Projects of China (18ZDA102), 2018.

This work was supported by Natural Science Foundation of China (72004089), 2020.

Competing Interests: The authors declare that they have no conflict of interest.

Availability of data and materials: The datasets used and/or analyzed during the current study are available from the corresponding author on reasonable request.

\section{References}

Balassa, B. (1978). Exports and economic growth: further evidence. Journal of development Economics, 5(2), 181-189.

Couwenberg, J., Dommain, R., \& Joosten, H. (2010). Greenhouse gas fluxes from tropical peatlands in southeast Asia. Global Change Biology, 16(6), 1715-1732.

Dhehibi, B., El-Shahat, A. A. I. A., Frija, A., \& Hassan, A. A. (2016). Growth in Total factor productivity in the Egyptian agriculture sector: Growth accounting and econometric assessments of sources of growth. Sustainable Agriculture Research, 5(526-2016-37743).

Dogan, E., \& Seker, F. (2016). The influence of real output, renewable and non-renewable energy, trade and financial development on carbon emissions in the top renewable energy countries. Renewable and Sustainable Energy Reviews, 60, 1074-1085.

Faridi, M. Z. (2012). Contribution of agricultural exports to economic growth in Pakistan. Pakistan Journal of Commerce and Social Sciences (PJCSS), 6(1), 133-146.

Gokmenoglu, K. K., \& Taspinar, N. (2018). Testing the agriculture-induced EKC hypothesis: the case of Pakistan. Environmental Science and Pollution Research, 25(23), 22829-22841.

Higgs H (1897) The Physiocrats: six lectures on the French Économistes of the 18th century. Macmillan and Company, limited

Hou, Y., Velthof, G. L., \& Oenema, O. (2015). Mitigation of ammonia, nitrous oxide and methane emissions from manure management chains: A meta-analysis and integrated assessment. Global change biology, 21(3), 1293-1312.

Hou, Y., Velthof, G. L., \& Oenema, O. (2015). Mitigation of ammonia, nitrous oxide and methane emissions from manure management chains: A meta-analysis and integrated assessment. Global change biology, 21(3), 1293-1312.

Kao, C., \& Chiang, M. H. (2001). On the estimation and inference of a cointegrated regression in panel data. In Nonstationary panels, panel cointegration, and dynamic panels. Emerald Group Publishing Limited.

Liu, X., Zhang, S., \& Bae, J. (2017). The nexus of renewable energy-agriculture-environment in BRICS. Applied energy, 204, 489-496.

Majeed, M. T., \& Luni, T. (2019). Renewable energy, water, and environmental degradation: A global panel data approach. Pakistan Journal of Commerce and Social Sciences (PJCSS), 13(3), 749-778.

Mariantonietta, F., Alessia, S., Francesco, C., \& Giustina, P. (2018). GHG and cattle farming: CO-assessing the emissions and economic performances in Italy. Journal of Cleaner Production, 172, 3704-3712. 
Mariantonietta, F., Alessia, S., Francesco, C., \& Giustina, P. (2018). GHG and cattle farming: CO-assessing the emissions and economic performances in Italy. Journal of Cleaner Production, 172, 3704-3712.

Mohamad, R. S., Verrastro, V., Al Bitar, L., Roma, R., Moretti, M., \& Al Chami, Z. (2016). Effect of different agricultural practices on carbon emission and carbon stock in organic and conventional olive systems. Soil Research, 54(2), 173-181.

Pesaran, M. H., Shin, Y., \& Smith, R. J. (2001). Bounds testing approaches to the analysis of level relationships. Journal of applied econometrics, 16(3), 289-326.

Pretty, J. (2008). Agricultural sustainability: concepts, principles and evidence. Philosophical Transactions of the Royal Society B: Biological Sciences, 363(1491), 447-465.

Ramachandra, T. V., Aithal, B. H., \& Sreejith, K. (2015). GHG footprint of major cities in India. Renewable and Sustainable Energy Reviews, 44, 473-495.

Reynolds, T. W., Waddington, S. R., Anderson, C. L., Chew, A., True, Z., \& Cullen, A. (2015). Environmental impacts and constraints associated with the production of major food crops in Sub-Saharan Africa and South Asia. Food Security, 7(4), 795-822.

Sertoglu, K., Ugural, S., \& Bekun, F. V. (2017). The contribution of agricultural sector on economic growth of Nigeria. International Journal of Economics and Financial Issues, 7(1), 547-552.

Shaikh, A. (2011). The first great depression of the 21st century. Socialist register, 47.

Tiffin, R., \& Irz, X. (2006). Is agriculture the engine of growth?. Agricultural economics, 35(1), 79-89.

Victor Bekun, F., \& Akadiri, S. S. (2019). Poverty and agriculture in Southern Africa revisited: a panel causality perspective. SAGE Open, 9(1), 2158244019828853.

Voivodas, C. S. (1973). Exports, foreign capital inflow and economic growth. Journal of international Economics, 3(4), 337-349.

Waqar, A., Hira, K., Ullah, B., Khan, A., Shah, Z., Khan, F. A., \& Naz, R. M. M. (2014). Role of nitrogen fertilizer in crop productivity and environmental pollution. International Journal of Agriculture and Forestry, 4(3), 201-206.

Zhang, T., Wooster, M. J., Green, D. C., \& Main, B. (2015). New field-based agricultural biomass burning trace gas, PM2. 5, and black carbon emission ratios and factors measured in situ at crop residue fires in Eastern China. Atmospheric Environment, 121, 22-34.

Zhang, Y. J., Jin, Y. L., Chevallier, J., \& Shen, B. (2016). The effect of corruption on carbon dioxide emissions in APEC countries: a panel quantile regression analysis. Technological Forecasting and Social Change, 112, 220-227. 